\title{
REDUÇÃO DA INCIDÊNCIA DE TRINCAS TRANSVERSAIS EM AÇO MICROLIGADO AO NIÓBIO PRODUZIDO NA CSN*
}

\author{
Carlos Alexandre Azevedo ${ }^{1}$ \\ Fernando Paulucio Quinelato ${ }^{2}$ \\ Marcelo Vilela Moreira ${ }^{3}$ \\ Tatiane Santos Ferreira \\ André Luiz Vasconcellos da Costa e Silva ${ }^{5}$
}

\section{Resumo}

Aços microligados ao nióbio possuem grande aplicação na indústria automotiva, muitas vezes como itens de segurança. Estes aços possuem certa tendência à geração de trincas transversais de superfície em placas produzidas via lingotamento contínuo, principalmente se as variáveis de processo durante a solidificação não forem adequadas. Experimentalmente, verificou-se que a ocorrência de trincas estava associada à composição química e às variáveis de processo. Com base nestas observações, avaliações da literatura e simulações com software Thermocalc $^{\circledR}$, foram propostas alterações de composição química e ajuste na curva de oscilação, sendo este último considerado fator principal para a obtenção de placas isentas de trincas.

Palavras Chave: Aço Microligado ao Nióbio, Trinca Transversal; Lingotamento Contínuo.

\section{REDUCTION OF THE INCIDENCE OF TRANSVERSE CRACKS IN NIOBIUM MICROALLOYED STEEL PRODUCED AT CSN}

\section{Abstract}

Niobium microalloyed steels are widely used in the automotive industry, often as safety items. These steels have a tendency to occur transverse surface cracks in slabs produced by continuous casting, especially if process parameters during solidification are not working properly. Experimentally, it was observed that the occurrence of these defects was related to chemical composition and process parameters. Based on these observations, literature data and Thermo-calc ${ }^{\circledR}$ software simulations, changes in the chemical composition and in the oscillation strategy were proposed. The latter was considered the main factor for obtaining slabs free of cracks.

Keywords: Niobium Microalloyed Steels, Transverse Crack; Continuous Casting.

Engenheiro Especialista, Lingotamento Contínuo, CSN, Volta Redonda, RJ, Brasil.

Engenheiro de Desenvolvimento, Processo Solidificação, CSN, Volta Redonda, RJ, Brasil.

Engenheiro Especialista, Laminação a Quente, CSN, Volta Redonda, RJ, Brasil.

Estudante de Engenharia Metalúrgica, Estagiária Nível Superior, Lingotamento Contínuo, CSN, Volta Redonda, RJ, Brasil.

5 Engenheiro, PhD, Professor, Universidade Federal Fluminense (EEIMVR-UFF), Volta Redonda, $R J$, Brasil. 


\section{INTRODUÇÃO}

O controle de defeitos superficiais e internos em placas de aço provenientes de lingotamento contínuo é de grande importância, uma vez que estes defeitos poderão persistir após o processo de laminação. Dentre os defeitos superficiais possíveis, destaca-se a trinca transversal, que uma vez não removida da superfície da placa gera defeitos denominados esfoliações nas bobinas.
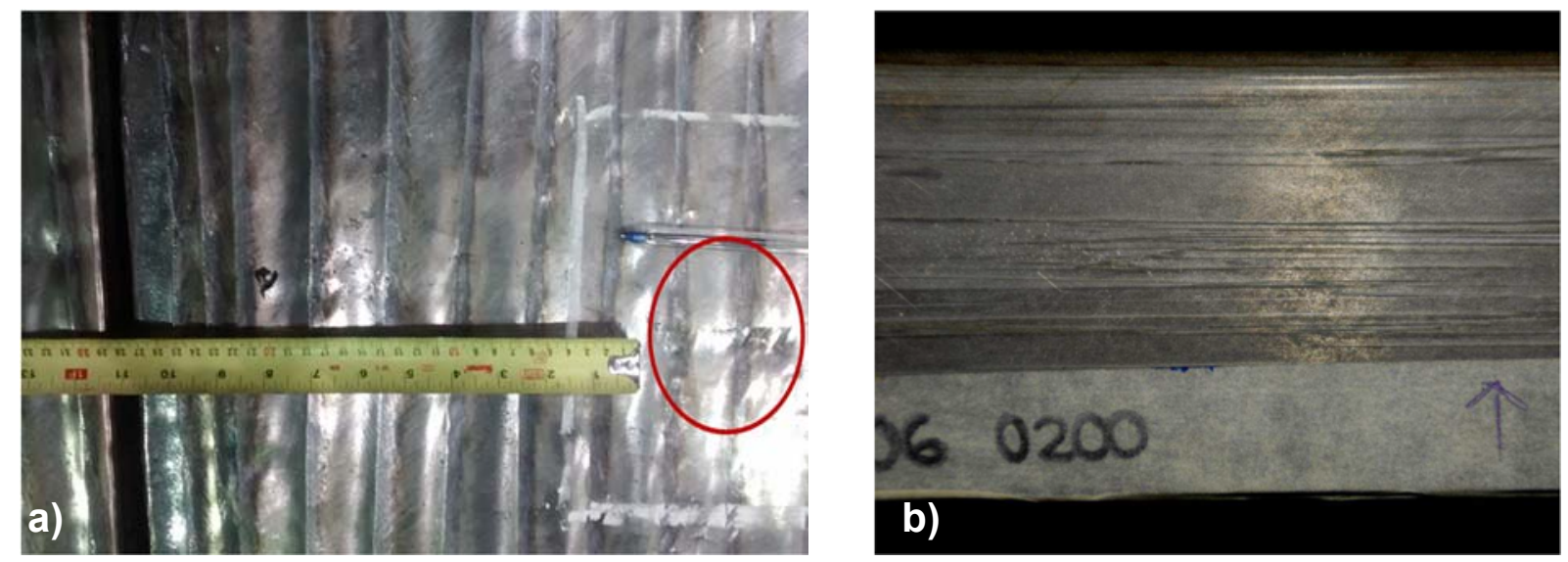

Figura 1. a) Trinca transversal em placa escarfada. b) Esfoliação em bobina.

Alguns tipos de aços possuem certa suscetibilidade à geração de trincas transversais. Entre estes estão os peritéticos microligados ao nióbio. A geração de trincas transversais durante o lingotamento depende de diversos fatores tais como composição química, superaquecimento, parâmetros de oscilação, transferência de calor no molde, controle de nível de aço no molde, refrigeração secundária, ajustes geométricos da máquina, projeto de máquina, dentre outros $[1,2,3]$.

No que se refere à composição química, alguns elementos são benéficos e outros deletérios à ductilidade a quente do aço. Quanto menor a ductilidade do aço a altas temperaturas, maior a probabilidade de geração de trincas transversais. Mintz [4] apresenta diversas relações entre elementos e seus efeitos na ductilidade a quente. A Figura 2 mostra que um aço com adição de $0,038 \%$ de nióbio possui menor capacidade de deformação a altas temperaturas e que o aumento do teor de alumínio em um aço com nióbio também exerce efeito negativo na ductilidade a quente. 

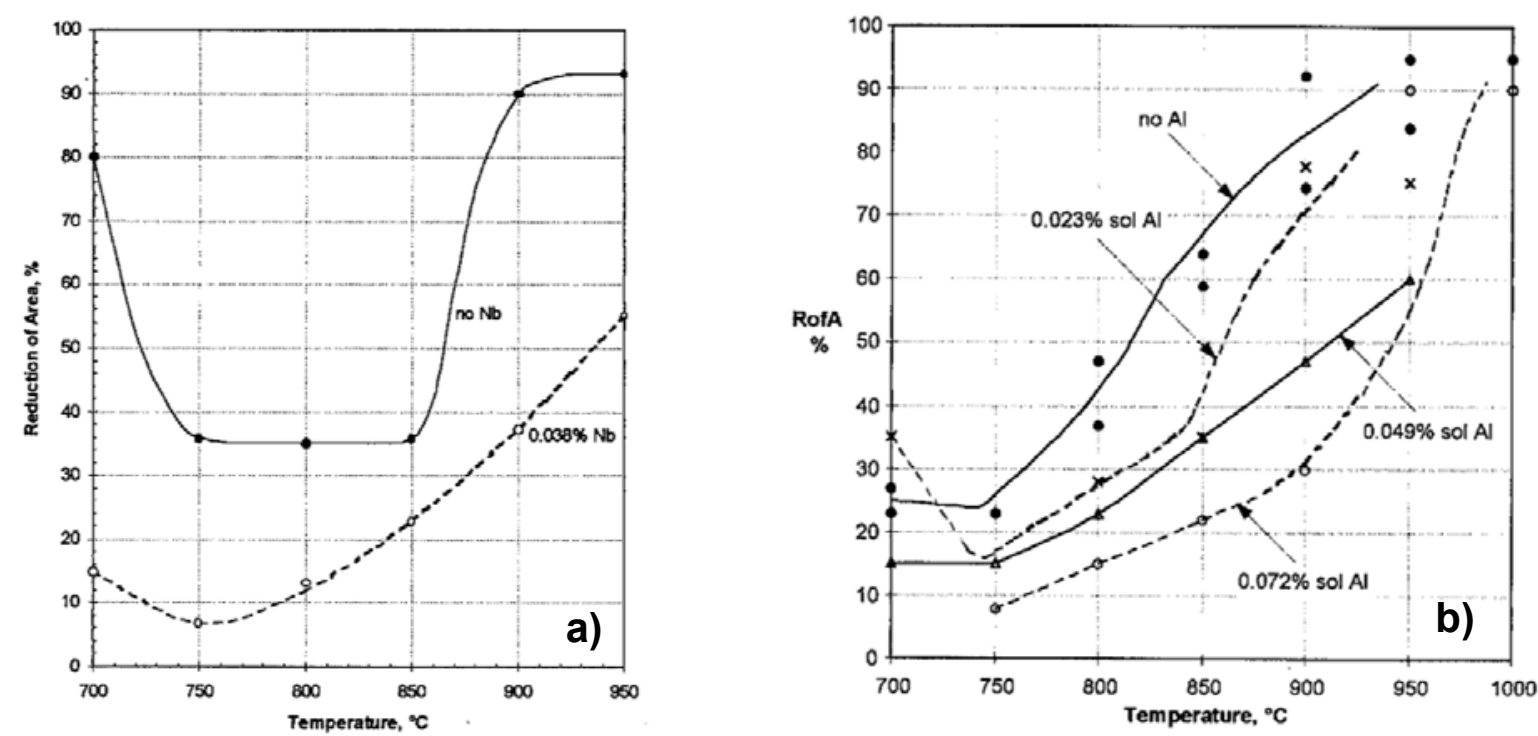

Figura 2. a) Influência do $\mathrm{Nb}$ na ductilidade a quente de aços. b) Influência do Al solúvel na ductilidade de um aço com $0,03 \%$ de $\mathrm{Nb}$. [4].

Mintz [4] apresenta, também, o efeito do enxofre em um aço C-Mn-Nb-Al. Nota-se que quanto maior o teor deste elemento, maior a perda de ductilidade no aço, que é atribuída à segregação para os contornos interdendríticos durante a solidificação. Outro elemento prejudicial à ductilidade a quente é o nitrogênio. $O$ efeito destes dois elementos sobre a ductilidade a quente são apresentados na Figura 3.
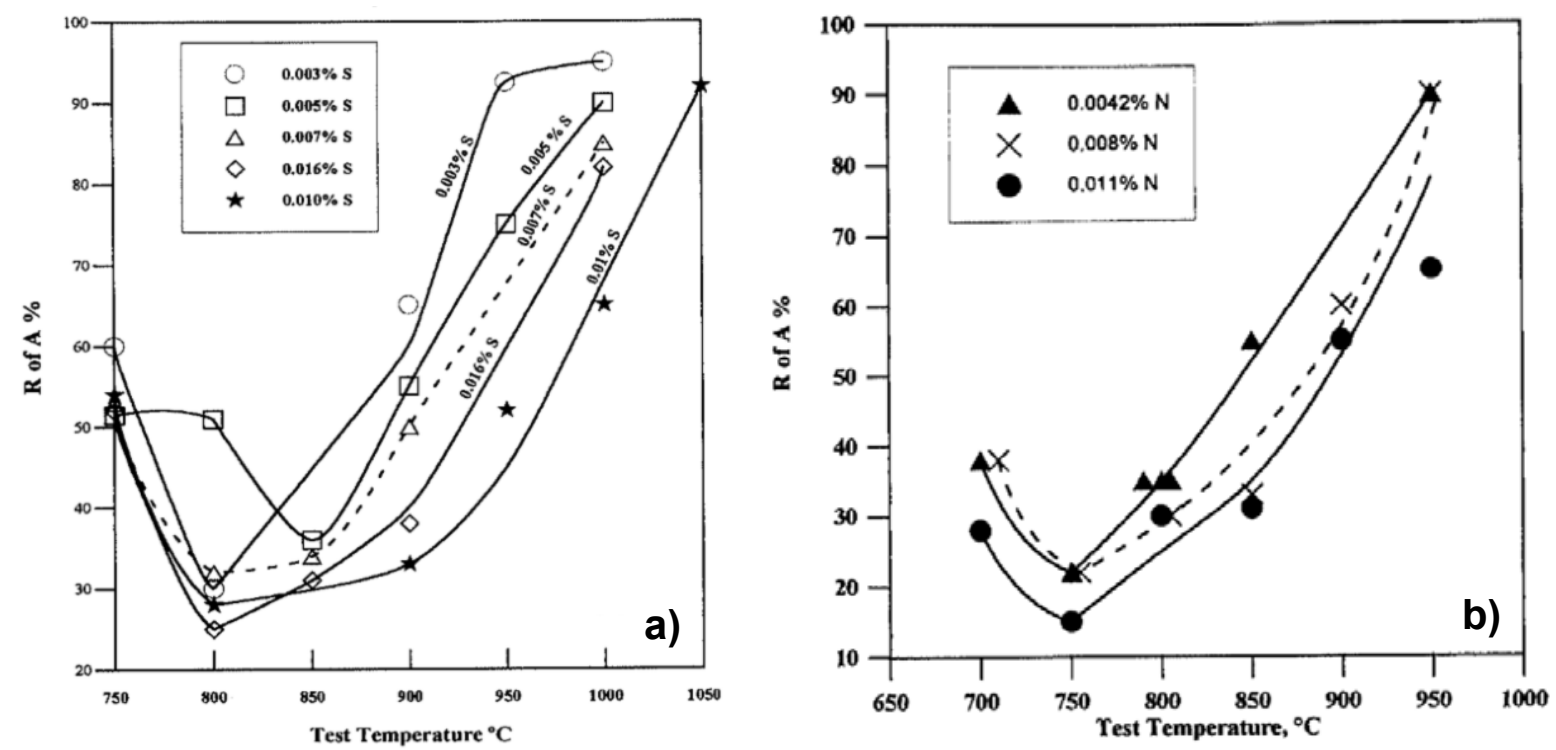

Figura 3. a) Influência do $S$ na ductilidade a quente de aços C-Mn-Nb-Al. b) Influência do $N$ na ductilidade a quente de aços C-Mn-Nb-Al. [4]

Alguns estudos citados por Mintz [4] mostram que quanto maior o produto [AI][N], maior será a perda de ductilidade devido ao processo de precipitação de AIN e portanto, maior tendência à formação de trincas transversais. Quanto maior esta relação, maior será a temperatura de início de precipitação de AIN: isto é, auxilia no 
crescimento e coalescimento dos mesmos, porém, existe a desvantagem de haver maior volume de precipitados. Assim, sempre que possível, é melhor trabalhar com baixos níveis de alumínio e nitrogênio. Além disto, pequenas adições de titânio podem melhorar a ductilidade a quente e atenuar a geração de trincas transversais. Adições entre $0,01 \%$ e $0,02 \%$ para aços com $\mathrm{N}<0,0045 \%$ são efetivas, assim como é recomendado o uso de uma relação titânio:nitrogênio de 4-5:1 [4].

O carbono também possui grande influência na geração de trincas transversais, principalmente se o teor estiver dentro da faixa de transformação peritética nos aços. Aços com transformação peritética apresentam grande contração devido à estreita faixa de temperatura de solidificação e diferença de densidade entre a ferrita e a austenita, o que gera uma superfície rugosa ou com depressão na peça solidificada. O aspecto não uniforme da casca solidificada é resultado do contato intermitente com o molde e da redução da extração de calor, o que origina uma estrutura com grãos mais grosseiros e que são regiões mais suscetíveis à geração de trincas a quente [5].

As marcas de oscilação são fator importante e para que se forme uma trinca transversal no ponto de desencurvamento da máquina de lingotamento é necessária uma marca de oscilação bastante acentuada na superfície [5]. O teor de carbono influencia na profundidade das marcas de oscilação, sendo mais profundas para teores próximos de $0,010 \%$ de carbono, devido à transformação de fase peritética.

A profundidade das marcas de oscilação pode ser reduzida através do aumento da frequência de oscilação ou diminuição da amplitude de oscilação, que levam à diminuição do tempo de estripamento negativo, que é o parâmetro a ser controlado para obtenção de marcas menos profundas.

As trincas geralmente se formam na base das marcas de oscilação e se propagam de maneira intergranular através dos contornos de grãos austeníticos, sendo que precipitados ou filmes de ferrita que crescem ao redor dos contornos austeníticos facilitam a formação ou propagação da trinca [3].

Este trabalho tem por objetivo verificar as causas da geração de trincas transversais em um aço peritético microligado ao nióbio através de correlações entre composição química e parâmetros de processo aliadas a simulações via Thermo-calc ${ }^{\circledR}$ e a caracterizações laboratoriais.

\section{MATERIAIS E MÉTODOS}

O aço estudado possui a seguinte composição química:

Tabela 1. Composição química do aço

\begin{tabular}{cccccccccc}
\hline \multicolumn{10}{c}{ Elementos (\% em peso) } \\
\hline & $\mathrm{C}$ & $\mathrm{Mn}$ & $\mathrm{S}$ & $\mathrm{P}$ & $\mathrm{Si}$ & $\mathrm{Al}$ & $\mathrm{N}$ & $\mathrm{Nb}$ & $\mathrm{Ti}$ \\
Min. & 0,070 & 1,000 & - & - & 0,050 & 0,020 & 0,003 & 0,040 & - \\
Máx. & 0,100 & 1,200 & 0,007 & 0,020 & 0,150 & 0,050 & 0,009 & 0,055 & 0,010 \\
\hline
\end{tabular}


Visando verificar a origem da formação e de propagação das trincas, foi retirada uma amostra de aço diretamente da placa com superfície bruta de solidificação, que foi cortada e preparada seguindo os métodos de preparação de amostras de aço para microscopia. Foram realizadas análises no microscópio ótico e eletrônico de varredura.
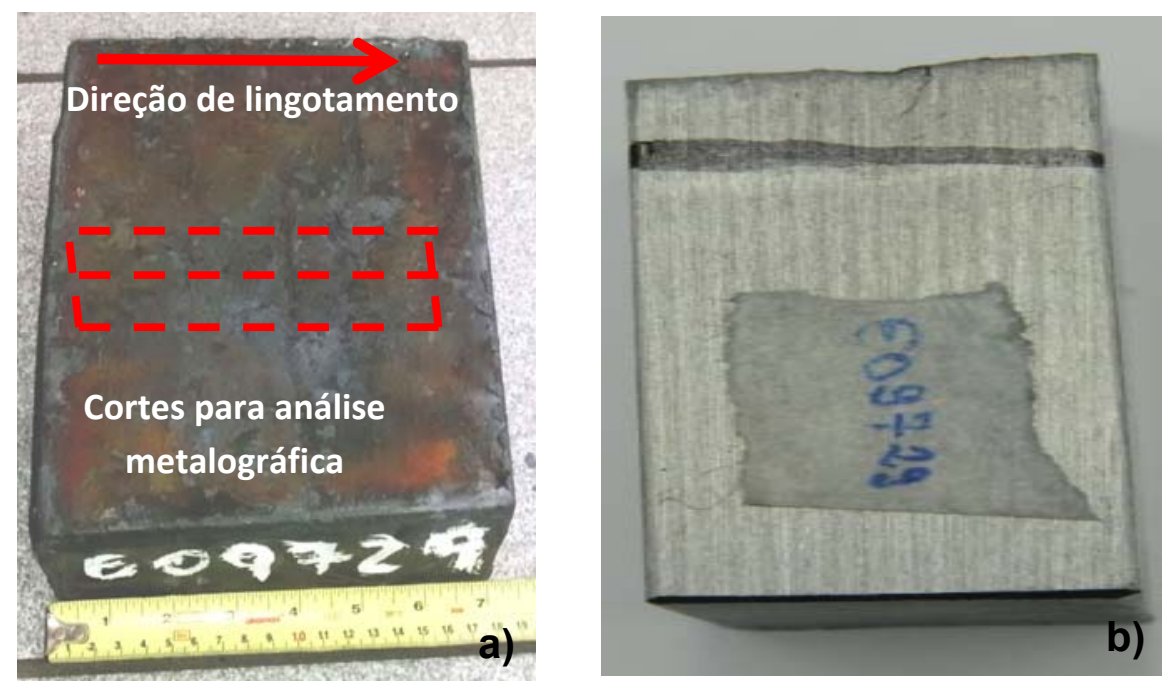

Figura 4. a) Amostra retirada da placa sem escarfagem. b) amostra cortada e encaminhada para análise metalográfica.

Foi realizada análise estatística para verificar as influências de carbono, alumínio, nitrogênio e nióbio na geração de trincas. Como indicador foi utilizado o percentual de placas com trincas transversais por corrida, relacionada a cada elemento mencionado anteriormente.

Com o auxílio do software Thermo-calc $^{\circledR}$ foram realizadas simulações com as alterações químicas propostas, que foram embasadas pela bibliografia e pela análise estatística citada anteriormente. O objetivo foi prever e comparar o comportamento da solidificação e início de precipitação para a composição original e a proposta.

Por fim, foi avaliado o impacto na utilização de uma nova estratégia de oscilação. Foi proposta a redução do tempo de estripamento negativo através do aumento da frequência e diminuição da amplitude.

\section{RESULTADOS E DISCUSSÃO}

Através das análises metalográficas foi possível verificar trincas nas bases das marcas de oscilação. Foi verificada a presença de supostos filmes de ferrita próeutetóide nos contornos de grão anteriores da austenita e também foram encontrados sulfetos e inclusões de alumina nas terminações das trincas, conforme apresentado nas Figuras 5, 6, 7 e 8. 

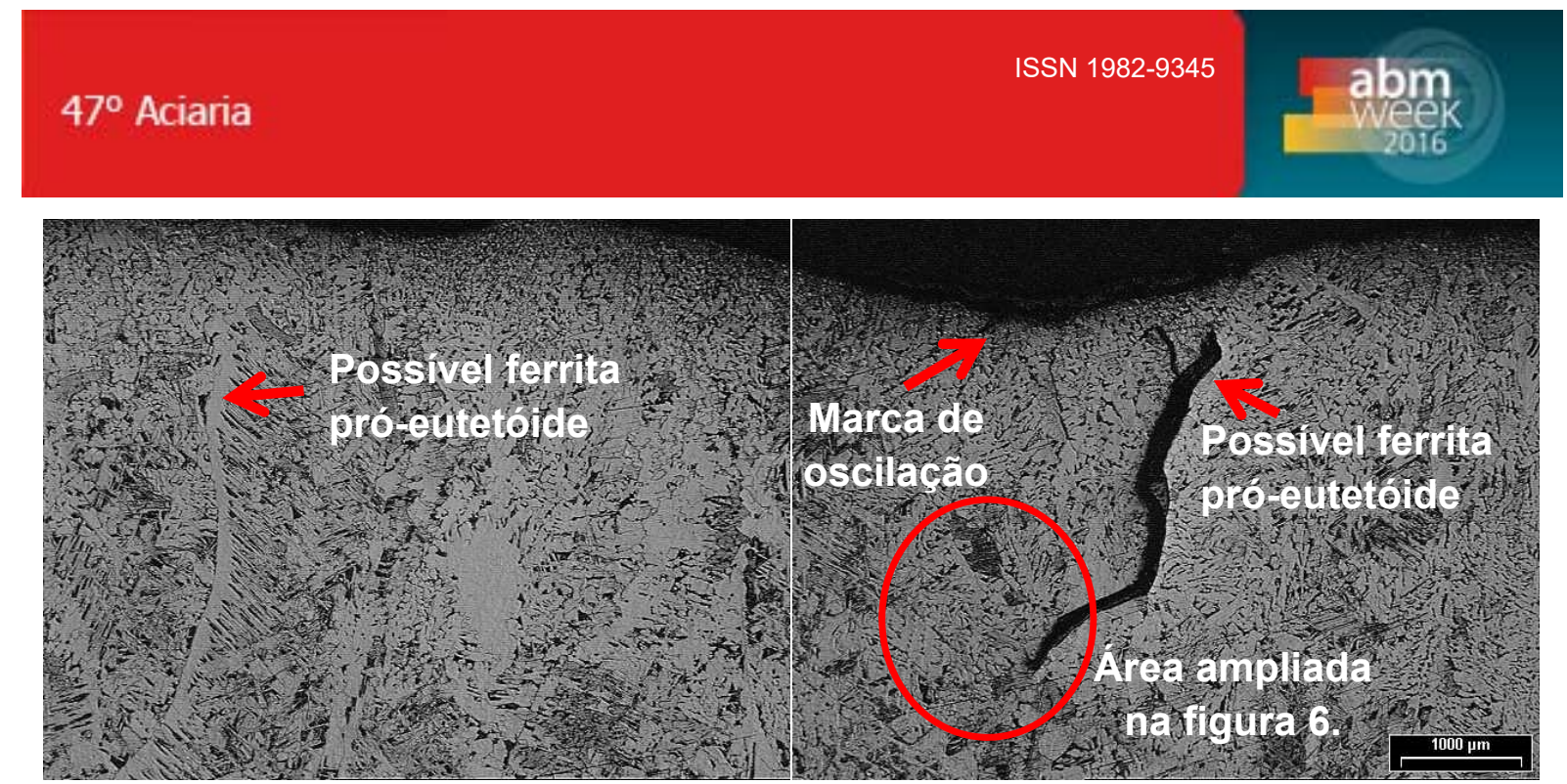

Figura 5. Micrografia com aumento de 12,5x.

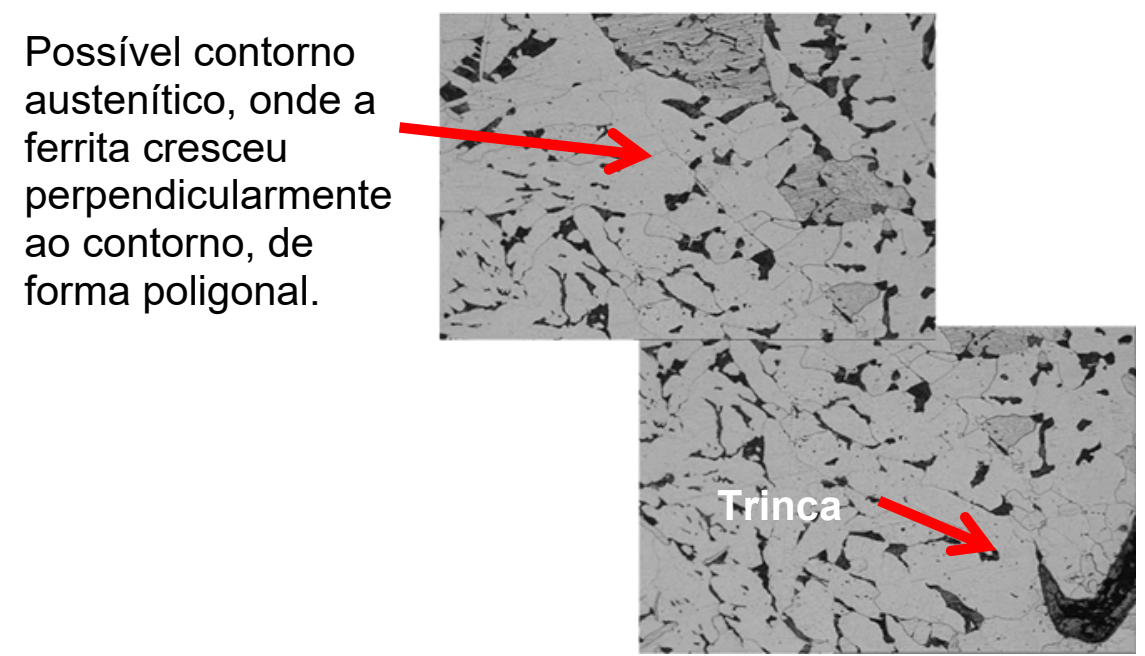

Figura 6. Ampliação de uma microrregião da figura 5. Aumento de 100x.

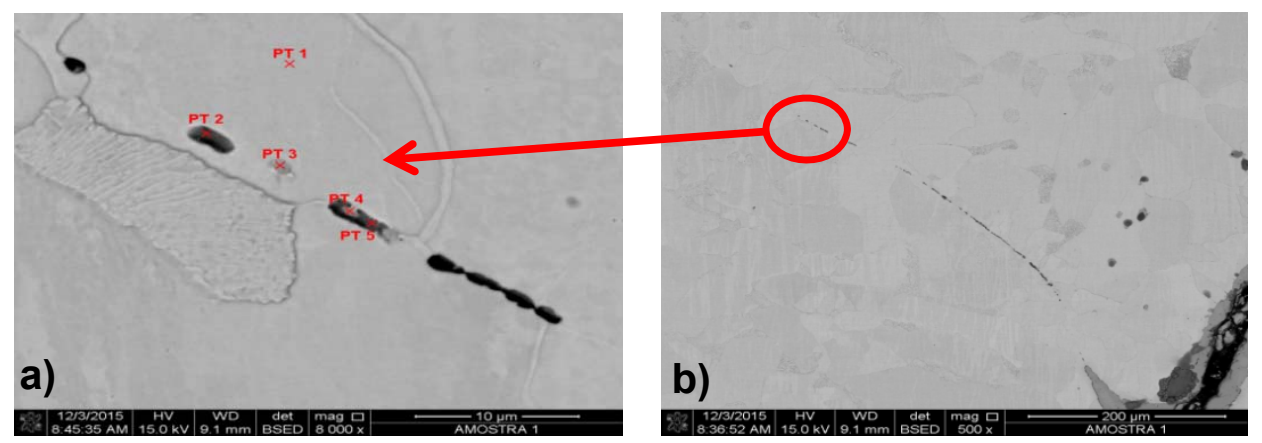

Figura 7. Imagem obtida por MEV, mostrando regiões de análise de EDS. a) aumento de 8.000x. b)aumento de 500x. 


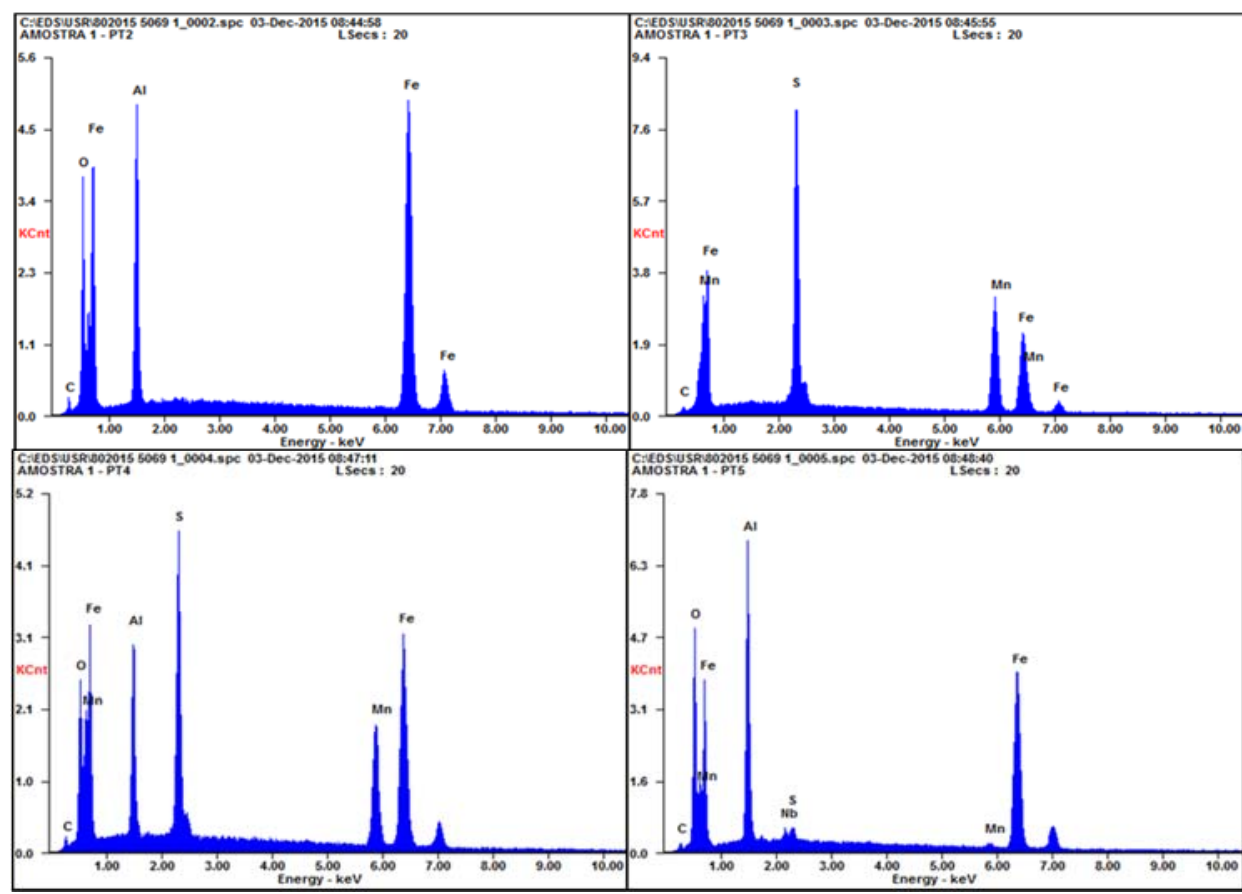

Figura 8. Resultados de análise por EDS.

Em outro corte foi possível detectar a presença de precipitados contendo nióbio, conforme apresentado na Figura 9.
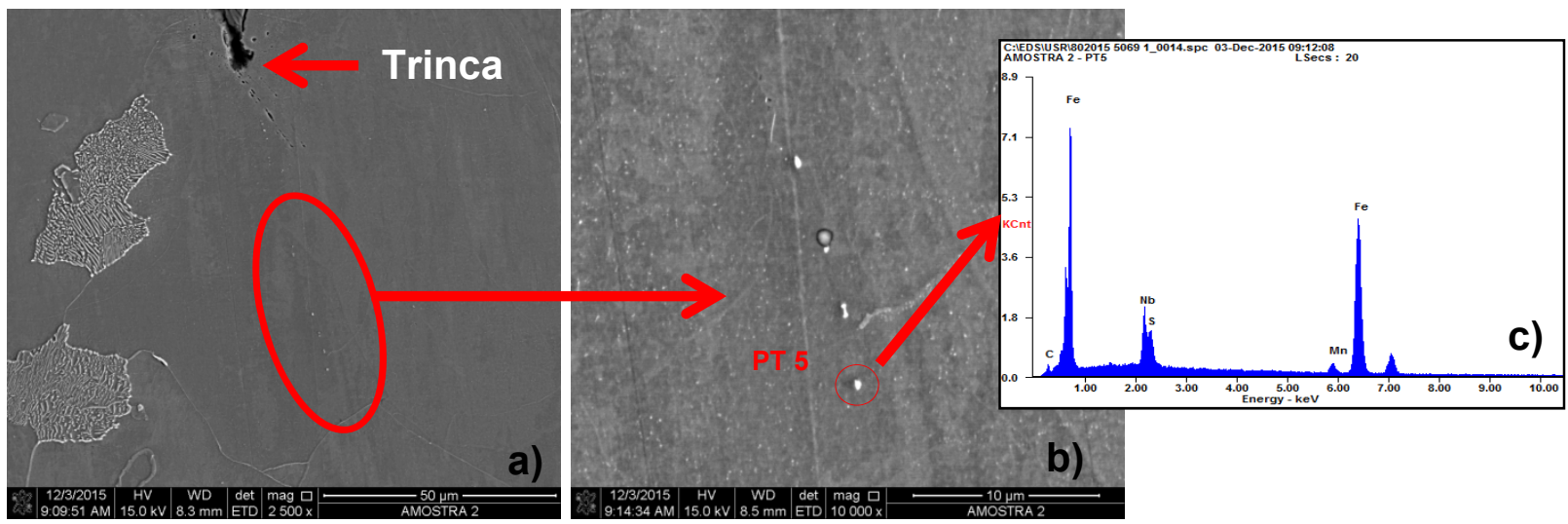

a)

b)

Figura 9. Imagem obtida por MEV-a) aumento de 2.500x, b) aumento de 10.000x. c) análise por EDS do ponto 5 mostrando pico de $\mathrm{Nb}$.

As análises metalográficas mostraram que as trincas se propagam por contornos de grão austeníticos prévios. De acordo com a literatura, essas trincas podem ocorrer devido à perda de ductilidade destas regiões a altas temperaturas, provocada por diversos fatores relacionados à composição química. Sendo assim, foi realizada análise estatística com objetivo de verificar tendência de geração de trincas relacionada ao teor de carbono, alumínio, nitrogênio e nióbio. Os gráficos a seguir correspondem à análise de 94 placas pertencentes a 11 corridas. O percentual é calculado dividindo-se do número de placas com trincas pelo número total de placas na corrida. 


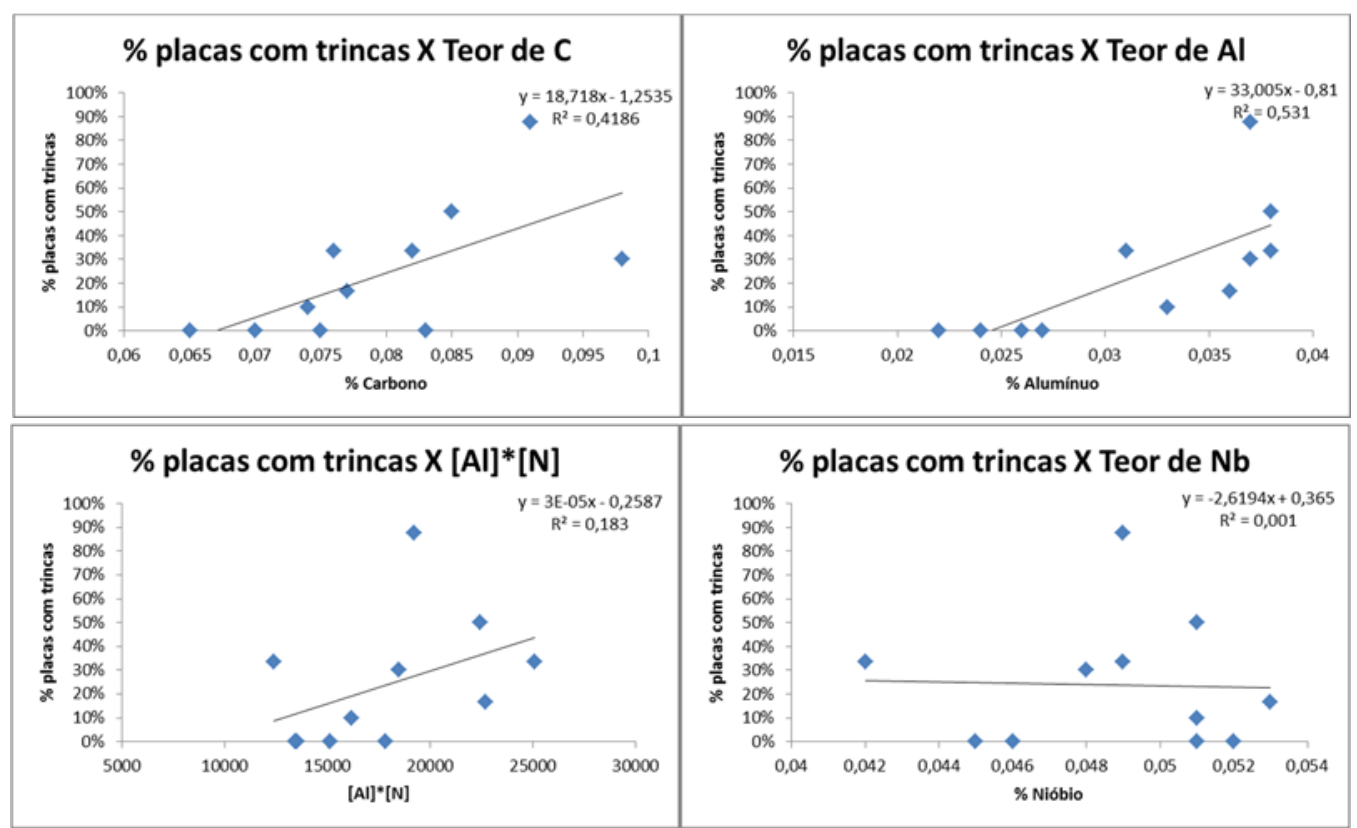

Figura 10. Correlações entre composição química e \% de placas com trincas por corrida.

Nota-se tendência de aumento de placas com trincas com o aumento dos teores de carbono e alumínio. De acordo com a literatura e com os resultados apresentados acima, foi proposta uma nova composição química com três alterações:

$1^{a}$ - Deslocamento da faixa de carbono em $0,01 \%$ para baixo, com o objetivo de evitar a região do início da faixa de transformação peritética;

$2^{\circ}$ - Deslocamento de $0,005 \%$ na faixa de alumínio para baixo, visando reduzir o produto $[\mathrm{Al}][\mathrm{N}]$;

$3^{\circ}$ - Eliminação da faixa de nitrogênio, fixando apenas teor máximo de 0,008\%.

Foi realizada simulação no Thermo-calc ${ }^{\circledR}$ para verificar a influência das alterações químicas durante a solidificação e os resultados são apresentados na Figura 11. As simulações foram realizadas utilizando os teores objetivados do aço, que são o meio das faixas de cada elemento. Elas mostram que o início de precipitação de nitretos de alumínio, AIN, se dará a uma temperatura mais baixa com o aço novo, o que é benéfico à ductilidade a quente de acordo com Mintz [4]. Nota-se também que haverá uma contração menor e menos acentuada no molde, o que confirma que a redução de 0,01\%, apesar de pequena, é bastante benéfica à lingotabilidade do aço. As propriedades finais após laminação foram verificadas de forma a garantir que as alterações químicas não provocassem desvio devido ao não atendimento às normas, o que não ocorreu. Não houve nenhuma alteração nos parâmetros de laminação. 

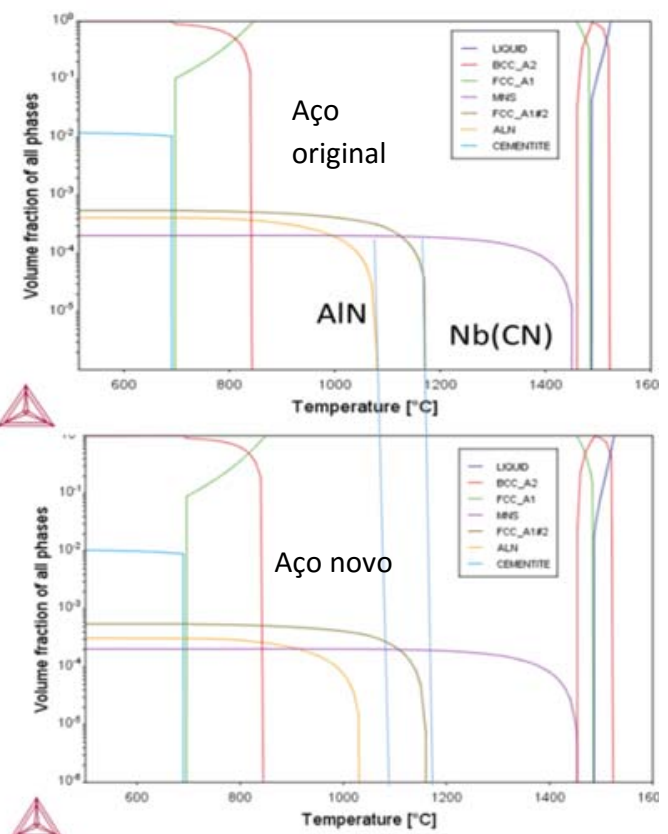

a)

Figura 11. Simulações obtidas pelo Thermo-calc ${ }^{\circledR}$ - a) Fração volumétrica $X$ temperatura de formação das fases. b) densidade do aço $X$ temperatura.

Mesmo com as alterações de composição, eventualmente, placas ainda apresentavam trincas. Tomando como base as análises metalográficas, que mostram que a trinca se origina na base da marca de oscilação, e a literatura, que associa as trincas às marcas, foi proposta uma nova curva de oscilação, onde o estripamento negativo é reduzido através do aumento da frequência e da redução da amplitude, conforme é apresentado na Figura 12. Os cálculos foram realizados com o software do fornecedor da Máquina de Corrida Contínua.

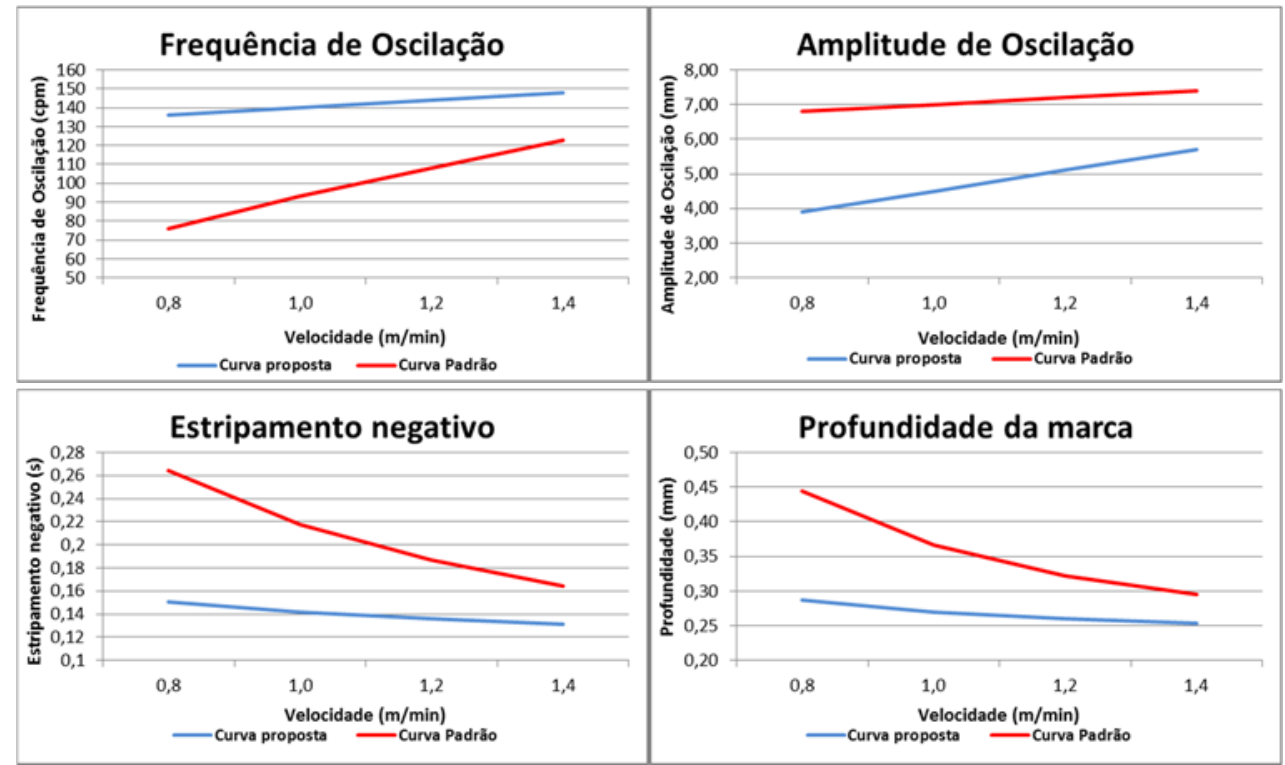

Figura 12. Parâmetros de oscilação e cálculo da profundidade da marca de oscilação. 
As alterações apresentadas anteriormente foram testadas e não apresentaram nenhuma interferência no processo, como por exemplo, aumento dos alarmes de rompimento de pele.

Com a nova curva de oscilação, praticamente não houve mais incidência de trincas transversais no aço estudado, isto em decorrência da redução da profundidade das marcas de oscilação, onde normalmente situam-se as trincas. A curva foi expandida para todos os aços peritéticos.

\section{CONCLUSÃO}

O presente trabalho mostra que os parâmetros de oscilação foram o principal fator para geração de trincas transversais. Outros parâmetros foram verificados, como por exemplo, a curva de refrigeração secundária e velocidade de lingotamento, entretanto, não houve intervenção em nenhuma destas ou outra variável.

Em relação à composição química, esta sempre deve ser levada em consideração, porém, em alguns casos, devido às restrições de norma, não é possível fazer alterações e isto não é impeditivo à produção de aços isentos de trincas transversais, pois, assim como verificado por Jansto [2], a composição não é o principal fator causal deste defeito.

Vale ressaltar que apesar de não ser fator principal, outros aços peritéticos com nenhuma ou menor adição de elementos de liga foram produzidos com a curva de oscilação antiga e não apresentaram trincas. Sendo assim, quanto maior a adição de certos elementos de liga, maior será a propensão à geração de trincas transversais devido a menor ductilidade a quente do aço, conforme apresentado no primeiro tópico deste trabalho. Nestes casos, o processo precisa estar bem ajustado para a obtenção de placas isentas de trincas.

\section{REFERÊNCIAS}

1 Jansto, Steven G. Hot Ductility Behavior in the Continuous Casting of Niobium-bearing Microalloyed Steels. 2013.

2 Jansto, Steven G. Steelmaking and Continuous Casting Process Metallurgy Factors Influencing Hot Ductility Behavior of Niobium Bearing Steels. 2013.

3 Tsai, H. T., Yin, H., Lowry, M. and Morales, S. Analysis of Transverse Corner Cracks on Slabs and Countermeasures, 2005.

4 Mintz, B. The Influence of composition on the Hot Ductility of Steels and to the Problem of Transverse Cracking. ISIJ International. Vol. 39. 1999. P 833-855.

5 Kliemann, L. P. Estudo da Formação de Trincas Transversais Faciais em Aços Peritéticos Produzidos no Lingotamento Contínuo. 2012. 